\title{
Os comunistas e as práticas de educação física dos jovens na década de 1930 no Rio de Janeiro'
}

\author{
Edivaldo Góis Junior² \\ Carmen Lucia Soares ${ }^{2}$
}

\section{Resumo}

Este estudo buscou compreender como eram construídas as representações dos comunistas sobre a educação física dos jovens, em contraposição com outras vertentes políticas na década de 1930, principalmente no Rio de Janeiro. Embora as juventudes e seus agrupamentos tivessem diferentes objetivos e origens, nossa pesquisa pretendeu demonstrar que os grupos tutelados por movimentos políticos, como a juventude comunista, buscavam nas práticas de educação física, que comungavam e atraíam os interesses dessa população, legitimar seus objetivos através de sua crescente atuação em grupos de jovens atletas. Em termos metodológicos, realizamos uma pesquisa documental que teve como fontes principais jornais influenciados pelo movimento comunista e, em segundo plano, aqueles produzidos pelo movimento integralista. Utilizamos, ainda, reportagens da grande imprensa. Esse conjunto de fontes foi publicado, principalmente, no Rio de Janeiro, em cujos arquivos foram encontrados 36 documentos produzidos entre 1930 e 1937, os quais foram analisados a partir das categorias juventude e educação física. 0 estudo concluiu que, para os comunistas, as associações juvenis populares, promovidas pela prática de esportes amadores, seriam espaços propícios para o estabelecimento de vínculos entre a juventude comunista e os jovens atletas. Os comunistas perceberam as associações esportivas constituídas por grupos de jovens como espaços de disputa com os integralistas, uma vez que a luta ocorria também no campo cultural e não somente no político. Fomentar uma frente ampla, impactar a cultura juvenil, aproximar-se de outras experiências de juventude, como os grupos esportivos, era preparar a revolução tanto no aspecto cultural, como no político.

\section{Palavras-chave}

Juventude - Comunismo - História da educação - Educação física.

1- Esta pesquisa contou com financiamento da Fundação de Amparo à Pesquisa do Estado de São Paulo (FAPESP), na modalidade "Auxílio a projeto de pesquisa regular", processo n²016/00617-6.

2- Unicamp, Campinas, SP, Brasil. Contatos: edivaldo@fef.unicamp.br; carmenls@unicamp.br

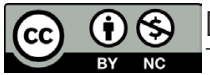




\section{Communists and practices of youth physical education in the 1930s in the city of Rio de Janeiro ${ }^{3}$}

\section{Abstract}

This study has sought to understand how communist representations of youth physical education were constructed, in contrast to other political trends in the 1930s, especially in the city of Rio de Janeiro. Although youths and their groups had different objectives and backgrounds, our research aimed to demonstrate that groups tutored by political movements, as is the case of the communist youth, sought - through physical education practices that shared and attracted the interests of this population - to legitimize their objectives by means of their growing involvement in groups of young athletes. In methodological terms, we conducted a documental research whose main sources were newspapers under the influence of the communist movement and, secondly, those produced by the "integralist" movement. We also used news stories from the mainstream press. This set of sources had been published mainly in the city of Rio de Janeiro, in whose archives we found 36 documents produced between 1930 and 1937, which were analyzed using the categories of youth and physical education. The study concluded that, for the communists, grassroots youth associations, fostered by the practice of amateur sports, were conducive to establish links between the communist youth and young athletes. The communists perceived the sports associations created by the youth as spaces of dispute with the "integralists" since the struggle took place not only in the political but also in the cultural field. Encouraging a broad front, impacting youth culture, getting closer to other youth experiences, such as sports groups, meant to prepare the revolution in both cultural and political aspects.

\section{Keywords}

Youth - Communism - History of education - Physical education.

\section{Introdução}

No dia 31 de maio de 1935, na cidade do Rio de Janeiro, um jornal chamado $A$ Manhã circulava nas ruas da então capital. 0 impresso era um veículo de propaganda política da Aliança Nacional Libertadora (ANL) que contava com o apoio de comunistas brasileiros. Um dos seus assíduos articulistas, Alvaro Moreyra ${ }^{4}$, intelectual simpatizante do Partido Comunista, estava preocupado com a juventude das cidades brasileiras. Naquela manhã, podiam-se ler seus argumentos, que descreviam o cotidiano das escolas cariocas:

3 - This work was supported by São Paulo Research Foundation, process number 2016/00617-6.

4- Alvaro Moreya (1888-1964) foi jornalista, editor, poeta, dramaturgo, ator, simpatizante do Partido Comunista e um dos membros da Aliança Nacional Libertadora (ANTUNES, 1999). 
A sineta tóca. Aula! Que chateação! Emquanto o professor explica a vida e a morte de Socrates, os alunos pensam em Sylvio e Jaguaré [jogadores de futebol]. Nos recreios seguintes, nas aulas seguintes, na sahida, no bonde, nas reuniões com os companheiros de bairro, emquanto não chega o somno, nenhum estudante péga num livro. Não tem tempo. Está ocupado pelo Botafogo, o Vasco, o Flamengo, o America, o S. Christóvão, o Fluminense, o Bangu... A cóla tambem constitue um “sport”. A passagem por média rasteira é um "goal" na certa. (MOREYRA, 1935b, p. 3).

O futebol, forte símbolo da vida moderna, invadia as cidades brasileiras, mobilizando juventudes. A ácida crítica de Moreyra, baseada, sobretudo, na forma como os esportes motivavam a juventude, era por vezes compartilhada e, por outras, contrariada por diferentes atores sociais oriundos de distintos grupos políticos.

Neste estudo, os esportes, mas também os jogos e as ginásticas, foram compreendidos como práticas culturais nas quais determinados grupos identificados pela representação de juventude imprimiam suas respectivas identidades. De maneira análoga, seria como observar o cinema ou o teatro, pois neles indivíduos e grupos dão sentido e significado tanto a expressões artísticas, quanto a determinadas práticas e representações (individuais ou coletivas) que, para Roger Chartier (2015, p. 7), "não são reflexos verdadeiros ou falsos da realidade", mas seriam construções que evidenciam as muitas divisões do mundo social. Da mesma forma, os esportes, os jogos e as ginásticas - que aqui serão convencionados pela expressão educação física - constituem-se como práticas ${ }^{5}$ que fabricam diferentes identidades, como as políticas.

São numerosos os estudos que relacionam a educação física a políticas nacionalistas, ao militarismo (HOLT, 1995), ao fascismo (SPURR, 2003), ao nazismo (REICHEL, 1999) e também ao integralismo brasileiro (SIMÕES, 2009); enfım, aí se vislumbram práticas de educação física relacionadas a um aspecto político autoritário e conservador. Contudo, seria necessário também pensarmos em outros grupos políticos e/ou religiosos, ou seja, em uma gama mais diversa de identidades que, nos mesmos tempo e espaço, buscavam as mesmas práticas voltadas ao corpo. Nesse caso, como seriam as representações sobre a educação física de grupos identificados com a ideia de juventude, mas sob diferentes perspectivas de cunho político?

Luís Antonio Groppo (2000), ao estudar as juventudes modernas, ensina-nos que a categoria social juventude vai além da determinação de uma faixa etária pautada em princípios biológicos e/ou fisiológicos. A juventude é construída socialmente a partir de uma representação ou criação simbólica identificada com determinados grupos sociais para significar comportamentos e atitudes atribuídos aos jovens.

Nesse sentido, compreender, em tempos específicos, as representações oriundas dessa categoria social juventude permite elucidar problemas relacionados às transformações da modernidade em diversos aspectos, como nas artes, nos divertimentos, no consumo, nas relações cotidianas e nas políticas não institucionais, sobretudo no século XX. As sociedades modernas, assim, podem ser explicadas para além das estruturas de classe, das estratificações sociais, ou seja, sua análise e sua explicação se constroem também

5- Neste artigo sempre que nos referirmos ao termo práticas estaremos nos baseando na acepção dada por Certeau (2011). 
a partir da categorização da infância, da velhice, da vida adulta, e, em nossa pesquisa, especificamente das juventudes. (GROPPO, 2000).

Ao enfrentar este problema, entendemos que existem diversas formas de viver a juventude. Assim, seria mais prudente falarmos em juventudes com determinadas particularidades (SAVAGE, 2009). Essa concepção carrega as identidades de grupos sociais concretos e heterogêneos formados por classes, estratos, etnias, religiões, diferenças de gênero, mundos urbano e rural (GROPP0, 2000). Dada tal diversidade, cada juventude pode, à sua maneira, reinterpretar a experiência de ser jovem, diferenciando-se dos adultos, das crianças, dos velhos, mas, sobretudo, de outras juventudes.

Essa categorização exige, portanto, uma delimitação mais precisa para a análise. Afinal, de qual juventude estamos falando? Para responder a essa indagação, exploramos a questão urbana e os embates das juventudes comunista e integralista.

Primeiramente, sobre a questão urbana, ao delimitarmos a pesquisa, interessou-nos especificamente as representações das juventudes brasileiras no contexto das cidades, principalmente no Rio de Janeiro, centro da estrutura político-administrativa do país na década de 1930. Isto porque "a cidade é uma concentração na qual esses problemas de representação têm toda a possibilidade de surgirem rotineiramente” (SENNETT, 2014, p. 66). A vida cotidiana pode ser concebida de muitos modos, a partir de estranhos que se tocam em uma população densa e heterogênea (SENNETT, 2014). Não seria diferente com os jovens, que conceberiam muitas formas de vivenciar esse tempo da vida na cidade.

Mesmo diante dessa caracterização de uma juventude urbana, foi também necessário compreender suas particularidades, as quais são evidenciadas pela formação de grupos heterogêneos. Para Groppo (2000, p. 42), em uma sociedade moderna, dada sua complexidade, "originam-se vários tipos de grupos e agências dirigidos à juventude", sendo inexequível uma organização unitária de um grupo etário por ela identificado. Porém, três tipos de grupos juvenis ganharam evidência no fim do século XIX e no início do século XX nas sociedades ocidentais: os grupos ligados ao sistema escolar, às agências juvenis controladas por adultos e, por último, os informais.

Primeiramente, a escola, como agência considerada civilizadora, estaria ocupada com a formação da juventude para a vida adulta, além da vida familiar. Em um projeto educacional moderno, a escola cumpriria objetivos de formação da juventude a partir do civismo, da ciência e da moral (CARVALHO, 1998). No Brasil, médicos, advogados, professores, militares, religiosos, políticos e escritores de posições políticas heterogêneas estavam imbuídos no debate sobre como a educação poderia modernizar o país. Para Marta Carvalho (1998), tais intelectuais vislumbraram a escola como agência capaz de criar estratégias de civilização, colocando a causa educacional como o principal problema nacional.

Em segundo lugar, as agências juvenis, controladas por adultos, tinham como meta a educação da juventude e, como objetivo, ocupar o tempo dos jovens em atividades culturais, recreativas e esportivas, criando grupos de escoteiros e bandeirantes, por exemplo. Nesse âmbito, temos, ainda, as agências organizadas por instituições políticas, que também buscavam o comprometimento dos jovens com uma causa de interesse das organizações, como foi o caso das juventudes integralista e comunista. A partir desta caracterização, podemos também incluir as agências governamentais ou filantrópicas com interesse nos jovens em situação de abandono (GROPPO, 2000). 
Concomitantemente à disseminação das escolas e agências juvenis controladas por adultos, surgia uma terceira tipificação: os grupos informais que, para Groppo (2000), almejavam uma identidade própria e autônoma, mas, paradoxalmente, buscavam também o reconhecimento da sociedade de forma mais ampla. Eles gozavam de certa autonomia, mas estavam ligados às agências modernas que tinham como interesse principal a juventude, pois eram criados a partir de reações inesperadas e/ou oposições à tutela dessas instituições.

Sem exercer completa independência no início do século XX, contudo, esses grupos juvenis informais foram paulatinamente constituídos a partir do crescimento dos espaços urbanos. Nos termos de Groppo (2000, p. 52-53):

0 lazer tornou-se um espaço e um tempo cada vez mais reconhecido pela sociedade e cada vez mais importante para os hábitos contemporâneos de consumo. Nele, os grupos juvenis informais encontraram momentos e locais extremamente favoráveis para o desenvolvimento de suas atividades diferenciadas e relativamente autônomas em relação aos adultos. Fugindo das instituições já sedimentadas da modernidade - o sistema escolar, as associações juvenis patrocinadas por adultos, a polícia, a justiça, o serviço militar etc., os grupos juvenis caíram nas malhas de novas instituições que eles próprios ajudaram a construir ou sedimentar.

Dessa maneira, como grupo social interessado nos divertimentos e em sua prática de maneira mais autônoma, os jovens estavam na vanguarda e na criação de espaços propícios para expressão das artes, organização de bailes e festas, bem como agremiações esportivas. (GROPPO, 2000).

É sobre este último aspecto que formulamos a problematização deste estudo, visando compreender as representações sobre a educação física dos jovens por parte dos comunistas na década de 1930, principalmente no Rio de Janeiro.

Embora as juventudes e seus agrupamentos tivessem diferentes objetivos, nossa pesquisa pretendeu demonstrar que grupos juvenis tutelados por movimentos políticos, como a juventude comunista, buscavam em práticas de educação física legitimar seus objetivos através de sua crescente atuação em grupos formais e informais de jovens atletas. Isto porque as práticas esportivas comungavam e atraíam os interesses das juventudes. Em outras palavras, perseguimos a hipótese de que a juventude comunista, buscando opor-se aos integralistas, almejava ampliar sua influência sobre os jovens, utilizando como estratégia práticas de educação física que eram disseminadas em um Brasil urbano, aqui representado, principalmente, pela cidade do Rio de Janeiro na década de 1930, período de conflito entre posições políticas antagônicas que coexistiam no país.

Para isso, em termos metodológicos, realizamos uma pesquisa documental que tomou como fontes jornais ${ }^{6}$ - principalmente os publicados no Rio de Janeiro - com posições políticas diversas, em que se vislumbra a influência de movimentos como o comunismo e o integralismo, mas também de uma grande imprensa identificada com diferentes interesses, às vezes de cunho liberal, outras vezes de cunho conservador. Nos arquivos foram encontrados 36 documentos produzidos entre 1930 e 1937, os quais foram analisados a partir das categorias juventude e educação física. No Brasil, especificamente

6- Os documentos foram encontrados no Arquivo Público de São Paulo e na Hemeroteca Digital da Biblioteca Nacional. 
no final do século XIX e no início do século XX, em um contexto de modernização, os principais jornais de São Paulo e do Rio de Janeiro alcançavam leitores de diferentes extratos sociais e campos profissionais, como o comércio, mas também o mundo do trabalho em sentido mais amplo. Tais veículos tornaram-se suporte na construção da visibilidade de inúmeras práticas culturais (CRUZ, 2000).

A análise dos dados empíricos permitiu constatar como diferentes grupos políticos fabricaram reinterpretações sobre as práticas de educação física das juventudes. Desse modo, os esportes, as ginásticas e os divertimentos podem ser usados no sentido de homogeneizar grupos sociais em um projeto coletivo, seduzindo os jovens em relação a determinada identidade política. A observação das práticas, pois, é fundamental para o tratamento de nosso problema de pesquisa. Para Certeau (2011, p. 165):

\footnotetext{
Mesmo intactas em si mesmas, as condutas se inscrevem em outras trajetórias sociais. Obedecem a critérios, classificam-se segundo categorias, visam a objetivos que mudam. Essas questões revelam uma formalidade das práticas (práticas de linguagem, práticas profissionais ou crentes etc.) [...] Uma das tarefas da história é medir a distância, ou as relações, entre as formalidades das práticas e das representações [...].
}

Ao realizar esta operação historiográfica (CERTEAU, 2011), cabe-nos, neste momento, perceber como a educação física pôde ser representada por diversos projetos políticos ligados às juventudes e como essas representações modificavam ou não as práticas.

\section{Da educação física de sempre: conservadora e disciplinadora das juventudes}

Quando representamos uma aula de educação física na escola do século passado, logo a imaginamos ligada a valores conservadores: a voz de comando, uma educação militarizada e também adestradora, onde cabe ao jovem apenas o subjugar perante a autoridade do professor. A educação física surge ali em traços mais carregados de disciplina do que outras que se desenvolviam naquele espaço, como era o caso do ensino da matemática, da escrita e da leitura, ou, ainda, da história e da geografia. Ao pensarmos sobre a expressão educação física, e ao a relacionarmos ao termo escola, é comum a imagem centralizadora por parte do professor, se comparamos com outras disciplinas escolares. Essa representação tem seu fundamento, uma vez que políticas nacionalistas de cunho autoritário que engendraram ditaduras, sobretudo a partir da década de 1930, ganharam centralidade na Alemanha e na Itália, por exemplo. Em ambos os casos, com os governos nazista e fascista, a educação física surgia com relevância nos projetos educacionais voltados às juventudes. Tão forte foi essa associação, que podemos pensar que políticas antifascistas, voltadas às juventudes, fossem contrárias à educação física por esta representar o adestramento do corpo, o controle, a coerção.

Pesquisas históricas (HOLT, 1995; SPURR, 2003; REICHEL, 1999; SOARES, 1994) evidenciaram esse aspecto em muitos contextos nacionais, a ponto de os próprios professores de educação física se identificarem como agentes do controle e do disciplinamento. Contudo, seria adequado refletir sobre essa vereda de estudos, principalmente no sentido 
de pensá-la não como a única representação do passado, mas, tão somente, como mais uma entre outras. Desse modo, seria possível problematizá-la situando-a no tempo e a partir de uma judiciosa interrogação às fontes, indagando se elas foram compartilhadas por posições políticas heterogêneas por parte das juventudes na década de 1930 .

Como dissemos, a associação mais óbvia seria entender a educação física em uma perspectiva de controle e disciplinamento das juventudes. Assim, os objetivos educacionais atrelados aos aspectos políticos conservadores nos levariam a uma primeira associação com movimentos juvenis ligados ao conservadorismo e ao autoritarismo.

Na década de 1930, no Brasil, muitos embates ideológicos internacionais reverberaram no país mediante algumas reapropriações. Foi o caso do integralismo, movimento político conservador e autoritário, inspirado no fascismo italiano (BERTONHA, 2008; CAVALARI, 1999). Sob o lema "Deus, Pátria e família", muitos jovens nas aglomerações urbanas brasileiras mais populosas aderiram ao movimento, sob os auspícios de ideias difundidas pelo seu idealizador, Plínio Salgado (FAGUNDES, 2012).

Segundo Renata Simões (2009), os esportes e a ginástica militar, mediante uma moralização do corpo, possibilitavam, tanto no fascismo, quanto no integralismo, a constituição de um fator de enquadramento e formação de soldados da nação. Assim, uma educação integral, pautada na moral, no intelectual e no físico, formaria o verdadeiro integralista, nos termos definidos por Plínio Salgado. "Por meio do discurso 'esportivizante' eram veiculados valores como a exaltação da presteza física e da autodisciplina, e formava-se o 'camisa-verde' 'forte de espírito e de músculos', atingindo seus fins morais, doutrinários e eugênicos” (SIMÕES, 2009, p. 131).

Ao descrevermos esses aspectos da educação dos jovens integralistas, a representação da educação física das juventudes como ferramenta de controle e disciplinamento é reforçada. Contudo, a partir de outra perspectiva - qual seja, da juventude comunista, que também era administrada por interesses exógenos aos jovens, sem gozar de plena autonomia, mas com uma perspectiva política antagonista ao integralismo, ao fascismo e ao nazismo -, as representações sobre educação física poderiam variar. Sendo assim, não haveria apenas uma única representação sobre educação física das juventudes na década de 1930, pois, ao tomarmos de forma antagônica outra experiência, outros objetivos e valores, poderiam ocorrer adesões e ressignificações de suas práticas. Se a educação física fosse um bloco sedimentado e único de uma prática conservadora e autoritária, então ela deveria ser criticada, evitada, combatida, tal como era a educação católica por parte dos comunistas. Dessa constatação inicial decorre uma de nossas indagações centrais: quais eram as representações dos comunistas sobre a educação física dos jovens no período?

\section{De uma outra educação física brasileira da década de 1930: espaços esportivos e a juventude comunista}

Na década de 1930, no Brasil, a juventude comunista ganhava mais adeptos, incentivada pela organização da Aliança Nacional Libertadora. A ANL tinha como principais bandeiras as lutas contra o imperialismo e o fascismo, congregando uma frente política ampla, com jornalistas, estudantes, artistas, educadores e os próprios comunistas pertencentes a distintos extratos sociais. No Rio de Janeiro, a ANL tinha grande influência 
sobre o jornal diário A Manhã, que, por sua vez, circulou sob a direção de Pedro Motta Lima, em 1935. 0 jornal ganhou notoriedade na opinião pública com a colaboração de textos de Alvaro Moreyra, Anísio Teixeira, Jorge Amado, Di Cavalcanti, Carlos Lacerda (BRASIL, 2015), e tinha como linha editorial ser uma voz da esquerda brasileira.

Em meados da década de 1930, mesmo com a repressão e a clandestinidade dos comunistas, a imprensa relacionada à ANL, tanto em São Paulo, como no Rio de Janeiro, efetivou uma campanha exaustiva contra o integralismo. Com mais críticas à Ação Integralista Brasileira (AIB) do que ao próprio Governo Vargas, os jornais comunistas disputavam a influência sobre as juventudes, evitando o crescimento daquele movimento conservador, combatendo-o insistentemente. Em 1935, os comícios da ANL proclamavam a luta contra o integralismo:

Promovido pelo nucleo de Ramos, na séde central, á rua Almirante Barroso no 1, reunião publica de propaganda, para os moradores de Ramos, Bom-sucesso e arredores, e de todos aquelles que queiram lutar, sinceramente, contra o imperialismo e o integralismo, bem como pela instituição das liberdades populares e a independencia economica do Brasil. (OS COMICIOS..., 1935, p. 7).

Os ânimos estavam muito acirrados: comunistas de um lado, integralistas de outro, uma opinião pública majoritariamente liberal e/ou conservadora e um governo ambíguo como o de Getúlio Vargas desenhavam o cenário para uma guerra de palavras, na qual se colocavam os jornais $A$ Manhã, no Rio, e $O$ Homem Livre, em São Paulo, como representantes da ANL; o jornal A Offensiva, por parte dos integralistas; o Jornal do Brasil, o Correio Paulistano e o Estado de São Paulo, como representantes da grande imprensa. 0 jornalista Alvaro Moreyra (1935a, p. 3), no jornal A Manhã, descreve o momento de antagonismos:

Aquellas camisas, importadas pretas da Italia e que se esverdearam na viagem; aquelles braços direitos endurecidos no ar, de mão aberta; aquelle sigma, que é uma cruz swastica mal copiada; aquelles anauês [palavra de origem tupi-guarani que tornou-se a saudação integralista] de veados em transe; os faniquitos oratorios do chefe; o senhor secretario Gustavo Barroso, secretario da Educação Physica, com uma bruta barriga; o senhor Madeira de Freitas entristecendo o paiz com suas graças...tudo, tudo o que a Acção exhibiu foi uma vergonha contra Deus, contra a pátria e contra a família... Depois, o senhor Plínio Salgado viu que a coisa era possível [...] E desandou em cima justamente da chamada Nova Lei de Segurança Nacional, tambem conhecida como Lei Monstro, que estava em preparo: [Alvaro Moreyra descreve o que teria dito Plínio Salgado sobre a lei] - "Se a lei vier, eu gritarei, por oito e meio milhões de kilometros quadrados, a quarenta e dois milhões de brasileiros: Eu prohibo a Liberal Democracia no Brasil”. De certo que não seria direito colocar o sr. Plínio Salgado na cadeia. Mas, no hospício, era uma boa obra de caridade.

Contudo, além de enfrentar os integralistas, era preciso enfrentar a repressão governamental e a opinião pública liberal. Se antes o jornal $A$ Manhã, a ANL e os comunistas tinham seus discursos voltados à oposição ferrenha ao integralismo, a grande imprensa estava mais preocupada em atacar os comunistas e os seus valores considerados 
contrários à moralidade brasileira cristã. 0 Jornal do Brasil, em 1936, dá grande notoriedade a um parecer do Deputado Alberto Alvares sobre a atuação dos comunistas no Brasil que culminou com a tentativa de revolução em 1935, acusando a propaganda comunista de defender, em seus comícios e panfletos, a:

\begin{abstract}
Absoluta supressão da legislação contra o aborto; intervenção abortiva gratuita nos hospitais do Estado; oposição contra o combate á prostituição; supressão das aberrações burguesas-capitalistas referentes a casamento e divorcio; registro oficial facultativo; educação socializada das crianças; suspensão de todas as penas para as aberrações sexuais, anistia de todos os criminosos sexuais condenados. Como se vê, uma loucura metodica, tendo por alvo aniquilar os povos e suas culturas e fazer da barbarie base da vida do Estado. (0 IMPORTANTE PARECER..., 1936, p. 13).
\end{abstract}

Mas a guerra não estava restrita às disputas na opinião pública. Ela se alastrava pelas ruas, em episódios de violência entre os jovens e suas bandeiras opostas: integralistas e comunistas. Estava presente também no campo cultural, no interior do qual havia disputas em relação à possibilidade de influência politica sobre grupos juvenis formais e informais. Particularmente, disputavam-se posições, articulações e, por último, a constituição de redes de relações sobre vários setores ligados às juventudes, como as associações esportivas, por exemplo. Nesse sentido, havia, por parte dos comunistas, o interesse em ampliar sua influência sobre os jovens associados em grupos formais e informais em torno das práticas esportivas. Se aquelas práticas específicas de educação física atraíam os interesses das juventudes, longe de se colocarem como uma juventude comunista oposta aos jovens atletas, com outros interesses, com o compromisso revolucionário, os jovens comunistas enxergaram a possibilidade de aproximação com outras juventudes a partir dos esportes, ampliando sua propaganda política em outros círculos. 0 próprio relatório de 1936, do Deputado Alberto Alvares, evidencia essa prerrogativa quando revela o apoio de associações esportivas à juventude comunista. Nas suas palavras:

A juventude comunista, que antigamente era apenas uma insignificante organização sectária, prepara atualmente um Congresso Pan-brasileiro da Juventude Operária, Estudante e Camponesa. Esse congresso já conseguiu o apoio das organizações desportivas, das organizações de estudantes, organizações operarias, etc. (O IMPORTANTE PARECER..., 1936, p. 13).

A grande imprensa, ainda em 1937, estava preocupada com o avanço da propaganda comunista entre os jovens. No artigo Os recursos da propaganda comunista, também era evidenciada a circulação dessa juventude nos meios esportivos. Desse modo, no campo cultural, os comunistas disseminavam seus pensamentos nos locais onde as juventudes estavam inseridas, sobretudo nas escolas, nas universidades e também em associações, clubes e círculos esportivos. É um indício relevante no sentido de compreender que grupos juvenis controlados por adultos, para usar a expressão de Groppo (2000), como a juventude comunista, estavam imbricados com grupos juvenis informais, organizados em torno de uma prática de educação física, ou até mesmo com grupos juvenis institucionalizados, como os universitários e os escolares. Os comunistas sabiam que, para uma vitória no 
campo político, era necessário impactar a cultura das juventudes, por isso o investimento nos jovens atletas. Em relato publicado no Jornal do Brasil:

Todos os meios são visados para a penetração nas escolas, nas universidades, nos meios esportivos, etc., mediante a criação de clubes, círculos recreativos, grupos excursionistas, sob cujos disfarces procuram os emissarios do Komintern inocular o virus comunista na mocidade do nosso continente. (OS RECURSOS..., 1937, p. 6).

0 jornal ainda afirmava que os comunistas brasileiros não estavam isolados e que mantinham relação com argentinos, uruguaios, chilenos e com a Internacional Comunista, muito interessada na inserção do comunismo entre os jovens. Se para a grande imprensa era preocupante a influência do comunismo entre os jovens, no que ainda era chamado no Brasil de mocidade, para a imprensa ligada à ANL, que congregava os comunistas, era motivo de comemoração o engajamento dessa juventude nas disputas políticas. Em entrevista ao jornal $A$ Manhã, o líder estudantil Hugo Romariz fala sobre os propósitos da organização do I Congresso da Juventude do Brasil, planejado em 1935, que, entretanto, foi cancelado em razão da repressão do governo Getúlio Vargas (PRIMO, 2006). Nesse documento é possivel perceber as principais bandeiras da juventude comunista expressas tanto em palavras quanto em imagens (Figura 1). Ali constatamos a analogia ao lema do Manifesto Comunista "Proletários de todo o mundo, uni-vos", tomado como tema do congresso: "Jovens uni-vos para o vosso $1^{\circ}$ congresso".

Figura 1 - 0 estudante Hugo Romariz, falando ao redactor d'A Manhã

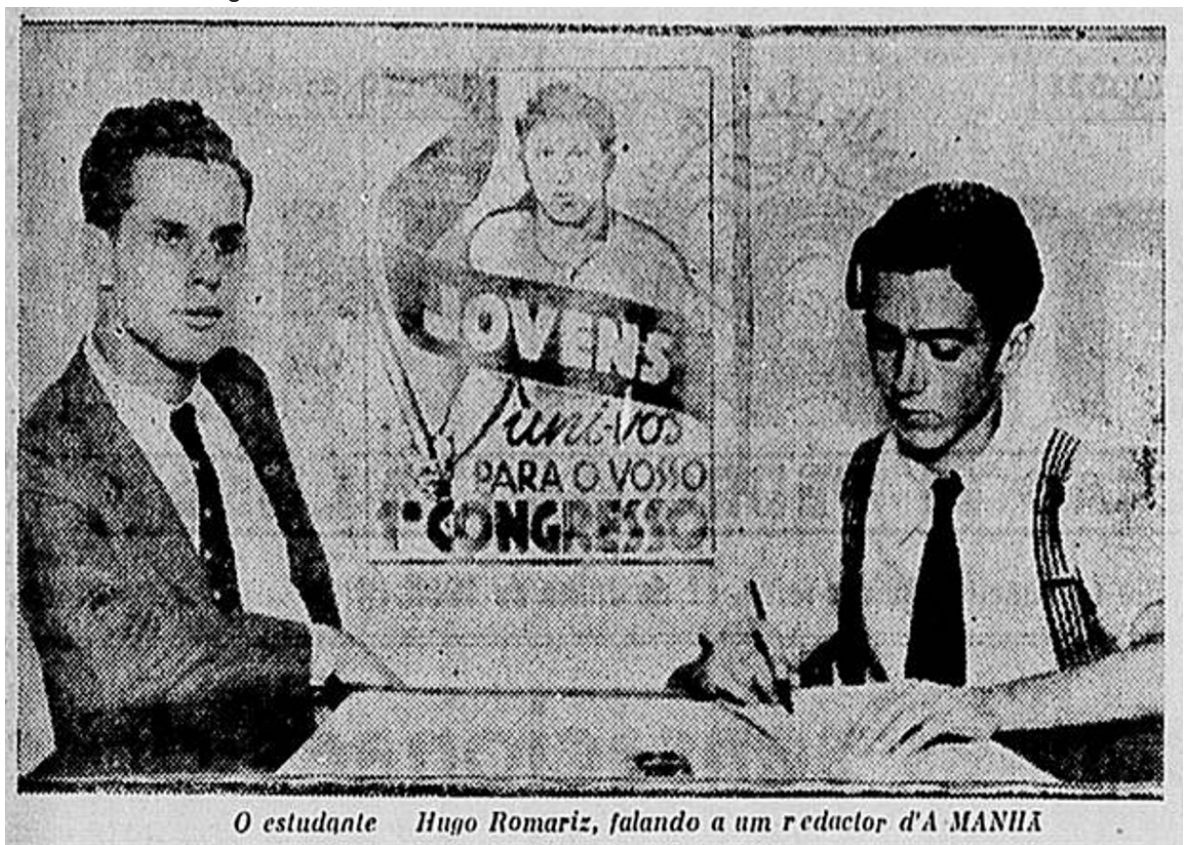

Fonte: As finalidades... (1935, p. 2). 


\section{Nas palavras de Hugo Romariz:}

Os capitalistas estrangeiros monopolizam todas as riquezas do paiz, nossos meios de transporte etc., e empregam grandes capitaes com ambições de lucros fabulosos, em detrimento de nossos trabalhadores que vêm seus salários cada vez mais diminuidos sob um maior numero de horas de labuta, tornando impossivel assegurar sua existência. [...] 0 Brasil está sob o jugo dos imperialistas estrangeiros. Estes para poderem nos explorar com mais vantagens, mystificam e impedem o desenvolvimento cultural de nosso povo. Por isso é que nosso paiz possue 75\% de analphabetos! [...] As adhesões ao Congresso aumengtam dia a dia, inclusive a de intellectuaes de projecção, organizações culturaes, sportivas, philosophicas, etc. na qual se vae traçar novos rumos para o Congresso, e para a qual appellamos, por intermédio desse brilhante jornal, para toda a mocidade em geral e todas organizações, sem compromissos conosco. (AS FINALIDADES..., 1935, p. 2).

A estratégia política de ampliação da influência sobre diversos grupos juvenis é evidenciada pela necessidade do Congresso em não se restringir à juventude comunista, pois era relevante atrair outras organizações "sem compromissos comnosco", ou seja, não adeptos do comunismo. Além disso, mais uma vez, a menção a "organizações culturaes, sportivas, philosophicas” demonstra a importância das práticas de educação física e dos grupos de jovens atletas no projeto comunista. Desse modo, caminhamos para a interpretação de que a educação física dos jovens constituía espaço de interesse para a atuação política. A partir desse pressuposto, os comunistas organizados na imprensa e nos grupos juvenis também tentavam evitar a disseminação de outras ideologias políticas, como o integralismo e o nazismo entre os esportistas. Um exemplo foi o jornal paulistano de influência comunista O Homem Livre, que, em 1933, denunciava, através de um depoimento anônimo, as alusões a símbolos e ideias nazistas no Esporte Clube Germânia ${ }^{7}$, atual Esporte Clube Pinheiros, utilizando-se do argumento de que os princípios racistas do nazismo constituíam uma evidente contradição à prática esportiva brasileira, que congregava os negros em suas equipes. Em seus termos:

Recebemos esta carta, datada de 5 de setembro de 1933, sob a assinatura de X. X., pseudônimo sob qual se esconde um alemão que pede desculpas por não poder assinar o seu nome verdadeiro, para não entregar os seus parentes na Alemanha ás fúrias vingativas dos Hitler, Goering e Cia. "Hitler decretou que as associações esportivas, por ocasião de suas sessões, devem fazer içar ao lado da bandeira nacional, a bandeira da cruz gamada. [...] Nas ultimas reuniões do Esporte Clube Germania, só se tem içado a bandeira gamada. [...] Considera o Fuhrer os brasileiros e japoneses, que são membros do Esporte Clube como arianos e como deve fazer então o Clube Germania quando tem que lutar com os outros clubes paulistanos, que tem em suas fileiras na qualidade de membros com iguais direitos, brasileiros de côr, que segundo Hitler, são idênticos aos judeus? Sabemos também que os membros arianos do Esporte Clube são absolutamente contrários á posição política partidária da direção do clube e, no entanto, como se conduz sua diretoria?” (0 SPORT CLUB..., 1933, p. 2).

\footnotetext{
7- Sobre o Esporte Clube Germânia, cf. QUITZAU; SOARES, 2010.
} 
Também no Rio de Janeiro, o jornal A Manhã estava atento em relação às associações entre práticas de educação física e movimentos políticos conservadores, sobretudo o integralismo. Em 1935, o tema central do VII Congresso Nacional de Educação estava ligado à educação física nas escolas (LINHALES, 2009). Naquele momento, a Associação Brasileira de Educação (ABE), para fomentar o tema, decide organizar, em parceria com órgãos públicos, uma parada desportiva, que foi realizada no dia 30 de junho de 1935.0 jornal A Manhã, sob a influência da ANL, apoiava a iniciativa; aliás, a despeito da presença marcante de liberais na $\mathrm{ABE}$, os comunistas tinham boa relação com alguns de seus líderes, como Anísio Teixeira, que, por sua vez, era acusado pela imprensa integralista de ser o comunista responsável pela "bolchevização do Districto Federal" (SÃO ESSES..., 1936, p. 4). Desse modo, nenhuma crítica foi proferida à realização do evento, mas havia uma forte preocupação com a possibilidade de jovens integralistas desfilarem no meio de algumas organizações, como a Escola de Educação Physica do Exército, liderada desde os anos de 1920 pelo coronel Newton Cavalcanti, que, segundo o jornal, era ligado ao integralista Pantaleão Pêssoa. Portanto, era preciso evitar qualquer demonstração simbólica de jovens integralistas no desfile. No noticiário:

\begin{abstract}
Estamos seguramente informados que na parada desportiva de domingo proximo [...], junto a este elemento, com surpresa geral, achar-se-á um contingente de 150 integralistas disfarçados em athletas. Como si isto não bastasse, para cumulo de tudo, a saudação dos contingentes militares será a saudação integralista! Iremos assistir os nossos soldados de mistura com o elemento plinesco, saudando a maneira plinesca as autoridades militares e civis que prestigiarão á parada. Entre essas autoridades estará o coronel Newton Cavalcanti, pessoa muito intima do chefe integralista Pantaleão Pêssoa, que naturalmente foi quem insuflou a esse coronel a saudação integralista a que devem ser obrigados nossos briosos soldados. (A PARADA..., 1935, p. 7).
\end{abstract}

Entretanto, depois da realização do desfile, as manifestações integralistas não ocorreram, e o jornal $A$ Manhã relatou com muitos elogios a iniciativa da ABE, conforme se pode ler:

Foi soberbo, sob todos os motivos, o espectaculo que, antehontem, foi oferecido á população carioca pela Associação Brasileira de Educação, fazendo desfilar cerca de 15 mil athletas numa demonstração vibrante de força e de vigor de nossa mocidade. É essa parada de musculos, muito embora realizada numa hora quasi impropria [14h30], teve a presencial-a um numeroso publico, que se concentrou em todo o trajecto do desfile para saudar os representantes da cultura physica brasileira. (0 DESFILE..., 1935, p. 4).

Se a relação com a $\mathrm{ABE}$, sobretudo com um dos seus líderes, Anísio Teixeira, era de respeito, o mesmo não ocorria com o Ministro da Educação e Saúde, Gustavo Capanema. Antes mesmo da ditadura do Estado Novo, em 1937, Capanema tinha o objetivo de aprovar um Plano Nacional de Educação que foi abortado (CURY, 2006), sendo, contudo, divulgado à imprensa em 1935. 0 jornal A Manhã, no artigo As bases fascistas clericais do Plano Nacional de Educação, criticou todos os aspectos do discurso de Capanema, ressaltando a influência dos setores religiosos e o caráter autoritário de sua proposta educacional. Além 
disso, o tema da educação física também foi abordado por Capanema, o que, para o periódico de influência comunista, demonstrava suas incoerências, pois, ao enaltecer a educação física, o ministro criticava os pressupostos da educação religiosa e medieval, justamente os mesmos presentes em seu Plano Nacional de Educação. Em seus termos:

Por isso, depois de ter celebrado os esportes, a beleza da força physica, do corpo humano, o ministro da Educação e Saude Publica do Brasil aconselhou isto aos professores brasileiros: - "Ensinemos o brasileiro a ser humilde e miserável para sentir a eternidade!” Mas então, dr. Capanema, por que o sr. fez tanta força para ser ministro? [..] Porque não anda rotinho e pedindo esmola? (AS BASES..., 1935, p. 7).

As práticas de educação física eram, portanto, vistas como estratégias de congraçamento das juventudes, por isso eram relevantes para o governo. Mas essas práticas não eram apenas importantes para os setores governamentais; também o eram para grupos políticos incutirem e disseminarem suas propagandas. Foi assim com os integralistas e comunistas que também disputavam espaço no interior dos clubes esportivos. 0 jornal $A$ Manhã relata um caso de perseguição dos integralistas a jovens esportistas cariocas que não aderiram às ideias de Plínio Salgado:

Em principio, o chefe do núcleo integralista tentou catechisar os socios do "Pereira Passos" [Clube de futebol amador], depois, repelido delicada e categoricamente pelos trabalhadores, entrou a perseguil-os. Assim, sob a alegação de serem os “footballers" vermelhos, conseguiu uma patrulha de Cavallaria da policia - tambem integralista - que, nos dias de reunião, se põe ostensivamente deante da séde do club prohibindo a permanencia dos rapazes na calçada... (OS INTEGRALISTAS PERSEGUEM..., 1935, P. 2).

A investida em relação aos clubes esportivos por parte dos comunistas, contudo, tinha outras características. 0 jornal A Manhã era um veículo de impressa que fomentava a aproximação com os clubes esportivos de subúrbio - ou seja, mais populares - e, nesse sentido, noticiava eventos relacionados com tais associações. Exemplos eram publicados na coluna A Manhã entre os pequenos clubes, com notas sobre o Sport Club Benfica, o Sport Club União, o Sport Club Guararapes, o Hanseatica Football Club, o Sport Club Fatima e o Sport Club Primor. 0 último parabeniza o jornal $A$ Manhã na seguinte nota:

Ilmo sr. redactor da secção de sport da A Manhã - cordiaes saudações. Este tem por fim felicital-o pela forma digna e brilhante com que o caro redactor vem desenvolvendo esta página, fazendo jús assim á sympathia não só dos grandes clubs, como tambem pertencemos. Communicamoslhe tambem que em assembléa geral foi este grande matutino aclamado nosso órgão oficial. (A MANHÃ..., 1935, p. 5).

Destacamos, também, o incentivo por parte do jornal $A$ Manhã para a criação de novos clubes esportivos populares, como o Centro Sportivo Tupynanbá, cujos princípios amadores são enaltecidos pelo noticiário. 
Em Honorio Gurgel, na linha auxiliar, os pequenos clubs, têm tido um desenvolvimento digno de nota, orientados por uma dúzia de esforçados sportmen, que não se deixam levar pelo mercantilismo da moda, mas querem a pratica de sports com a alevantada finalidade, que a caracteriza, isto é, o desenvolvimento do physico e o aperfeiçoamento da moral da mocidade. [...] A A Manhã falou ao sr. Bristol do formidavel programma que tem a realizar, com a creação de uma entidade popular, que concentre as forças sportivas de pequenos clubs, que entemdem o sport como o alto objetivo que elle tem. (OS SUCESSOS..., 1935, p. 3).

Um clube esportivo popular tinha que ter características que o diferenciassem dos grandes clubes da cidade do Rio de Janeiro, como Flamengo, Vasco, Bangu, Botafogo, América e Fluminense, nenhum deles considerado popular pelos comunistas, pois tinham aderido ao profissionalismo no futebol. Desse modo, o pequeno clube popular precisava ser amador para, desta maneira, cumprir seus objetivos junto às juventudes. Então, o jornal A Manhã apresentou uma série de reportagens sobre as vantagens do amadorismo e as desvantagens do profissionalismo, entrevistando ex-atletas de futebol. No artigo intitulado Sob os aspectos sportivo, social, intellectual e moral, comparará o publico o amadorismo e o profissionalismo!, aludia o jornal:

"A Manhã" confiará á população sportiva da cidade a tarefa de comparar os antigos campeões da cidade, sob o tríplice aspecto sportivo, social e moral com os jogadores da actualidade, afim de que julgue, afınal, o quanto tem sido nociva, entre nós, a implantação do profissionalismo, e, impariotica, a mercantilização da educação physica. (SOB OS ASPECTOS..., 1935, p. 5).

Compreender que o amadorismo esportivo era uma bandeira da imprensa comunista no Rio de Janeiro na década de 1930 é um dado importante, pois, em tal visão, o amadorismo não era um valor elitista. Ao contrário, o profissionalismo e a consequente mercantilização dos jogadores eram os problemas para o acesso popular aos esportes. Desse modo, era preciso que as práticas de educação física fossem mais democráticas, pois possibilitariam livres associações no seio da juventude popular. Posteriormente, seria estratégica a aproximação da juventude comunista com estes clubes, o que podia ocorrer a partir, por exemplo, da ampliação do espaço editorial de divulgação dos jovens atletas e seus pequenos clubes naquele jornal. Em 1935, buscando esse objetivo, o jornal A Manhã promoveu um concurso entre os atletas e as torcedoras de pequenos clubes de subúrbio:

No suburbio carioca e entre os pequenos club, causou grande satisfação e maior animação a noticia de que A MANHÃ abriria um concurso, para eleger o maior jogador e a mais popular "torcedora" dos gremios suburbanos, que tanto contribuem para o incremento do sports e o seu desenvolvimento.[...] Quem conhece, de perto, a vida dos pequenos clubs, os sacrificios de seus diretores, o enthusiasmo de seus amadores, é que póde constatar como se pratica, de facto, sport por sport, o puro amadorismo, que resiste a todas as investidas dos mercantilisadores da educação physica, que vêm nessa nova modalidade de negocio uma fonte rendosa para emprego de capitaes. (O SENSACIONAL..., 1935, p. 7). 
Por certo, esse investimento nas práticas de educação física despertava adeptos em diversos setores políticos da sociedade, como demonstramos aqui, mas também motivava desconfianças por parte de alguns liberais e comunistas, sobretudo de alguns intelectuais. A rápida popularização dos esportes, principalmente do futebol, na década de 1930, incomodava Alvaro Moreyra pela exagerada importância de que os esportes gozavam entre os jovens, em detrimento de outros aspectos da cultura. Ele não se opunha à educação física, mas sim à sua centralidade na educação daqueles tempos. Aludia o intelectual, no artigo intitulado Acompanhando o cambio:

Creio que seja optima a educação physica. Principalmente quando não se torna idéa fixa, e única idéa capaz de se manter na gente nova. Assim, fica sendo falta de educação. De corpo musculoso, hombros largos, peito aberto, pernas ágeis, sem carnes inúteis, os rapazes de hoje organizam, para os olhos de quem gosta, um espectaculo agradável. Porém põem nos ouvidos de quem não gosta, a peor das sensações.

No Brasil, o exagero e a afobação são estados de nascença; Antes, se fazia força para os domar, estylisar. Agora, a força é para os desenvolver..

0 "sport", detalhe da vida, appareceu aqui e expulsou o resto da vida. No resto, estava o essencial... Ganhamos, então, grandes jogadores de "foot-ball", grandes remadores, grandes nadadores. Multiplicamos as quadras de tennis, as piscinas, os cestos. 0 "box" já apresenta campeões nacionais. (MOREYRA, 1935b, p. 3).

Não se tratava de uma opinião particular motivada por uma ideologia comunista, pois a desconfiança e a crítica aos exageros eram comungadas por alguns médicos e jornalistas. Para eles, os jovens teriam que evitar os excessos. Se para Moreyra era preciso também cuidar de outros aspectos da cultura, para Carlos Fernandes, no artigo Cultura Physica, era preciso separar a prática de uma educação física como a ginástica - para ele, mais científica e racional - dos exageros dos esportes:

Não sei se chegamos a compreender que o aprumo, a destreza e airosidade britânica, apesar do whisky e do tabaco, se derivam quase que exclusivamente daqueles sadios hábitos de exercitação muscular. Seja como for, adotamos aqueles jogos, nacionalizamos a peteca, e chegamos ao exagero de erigir o football como mania pandêmica, que se manifesta em acessos hebdomadários de ameaçador e contagioso delirio. Assim estamos fabricando uma geração masculina de cangurus, pelo tamanho excessivo das pernas como já temos uma enorme plêiade de guaribas, pelo comprimento demasiado dos braços - os remadores. [...] Todavia é mister não confundir educação física com desportos. Estes caracterizam-se pela sua finalidade recreativa, que pode chegar ao atletismo ou ao comprometimento da saúde, da harmonia fisiológica. Aquela visa precisamente auxiliar, estimular e manter a euritimia do corpo humano. (FERNANDES, 1930, p. 1).

Tanto para Moreyra como para Fernandes, os jovens deveriam ser estimulados em relação às práticas de educação física, mas de forma tutelada, com objetivos específicos. $\mathrm{Na}$ grande imprensa havia uma tendência de promoção de muitas práticas de educação física, divulgando argumentos de críticos e defensores da ginástica, dos esportes, de ambos (GOIS 
JUNIOR; MELO; SOARES, 2015). É nesse aspecto que as representações dos comunistas são peculiares, pois, para eles, seriam os esportes amadores os progenitores de associações juvenis populares, evidenciadas pela propaganda jornalística de influência comunista, que estabeleceria vínculos entre a juventude comunista e os jovens atletas. Mesmo diante das desconfianças em relação aos exageros de uma "cultura physica" por parte dos jovens urbanos, os comunistas perceberam as associações esportivas como espaços de disputa com os integralistas, uma vez que a luta ocorria também no campo cultural, não somente no político. Fomentar uma frente ampla, aproximar-se de outras experiências de juventude, como os grupos esportivos, era preparar uma revolução política com importante base nos jovens. 0 plano não obteve êxito, contudo consolidou um forte ideário anticomunista no Brasil (SÁ MOTTA, 2002), preocupado com o aumento da capacidade de infiltração dos comunistas entre os jovens.

\section{Considerações finais}

Se nosso tema central de análise, que dá título ao artigo ora concluído, foram os comunistas e as práticas de educação física dos jovens na década de 1930, podemos afirmar que, ao folhear os jornais daquele tempo e buscar em suas páginas por esses traços, nosso artigo desejou, também, chamar a atenção para a miríade de possibilidades que ali existem. Em vez de pensar a juventude brasileira do período no singular, em vez de pensar a educação física, os esportes e as ginásticas como simples expressões de um pensamento e de uma prática autoritários e de pertencimento a uma única experiência de juventude, nosso propósito foi o de refinar as interrogações às fontes e, a partir do que se pôde ouvir e ler como respostas, narrar aqui este breve percurso.

A partir dele foi possivel perceber em que medida jovens de um período foram motivados pelos esportes e seus modos de organização, pela educação física e pelas ginásticas; foi possível, assim, pensar que tais práticas possuem variadas representações, nem sempre luminosas, heroicas, guerreiras ou, ainda, higienistas e eugênicas. Lendo textos e imagens, foi-nos possível, mesmo que de modo indelével, pensar quão extenso é o rol de interrogações que ainda necessitam ser feitas às práticas educacionais, inclusive as de educação física.

\section{Referências}

A MANHÃ entre os pequenos clubs. A Manhã, Rio de Janeiro, p. 5, 6 jul. 1935.

A PARADA desportiva de domingo - Não se deve, no bello espectaculo civico, fazer o cumprimento integralista. A Manhã, Rio de Janeiro, p. 7, 29 jun. 1935.

ANTUNES, Amauri Araujo. 0 trapézio ficou balançando: teatro de Alvaro Moreyra. 1999. Dissertação (Mestrado em Letras) - Instituto de Estudos da Linguagem, Universidade Estadual de Campinas (Unicamp), Campinas, 1999. 
AS BASES fascistas clericais do Plano Nacional de Educação. A Manhã, Rio de Janeiro, p. 7, 25 jun. 1935. AS FINALIDADES do I Congresso da Juventude do Brasil. A Manhã, Rio de Janeiro, p. 2, 11 jul. 1935.

BERTONHA, João Fábio. Sobre a direita: estudos sobre o fascismo, o nazismo e 0 integralismo. Maringá: EdUEM, 2008.

BRASIL, Bruno. A Manhã (Rio de Janeiro, 1935). Rio de Janeiro: Biblioteca Nacional, 2015.

CARVALHO, Marta Maria Chagas. Molde nacional e fôrma cívica: higiene, moral e trabalho no projeto da Associação Brasileira de Educação (1924-1931). 4. ed. Bragança Paulista: Edusf, 1998.

CAVALARI. Rosa. Integralismo: ideologia e organização de um partido de massa no Brasil (1932-1937). Bauru: EdUSC, 1999.

CERTEAU, Michel de. A escrita da história. Rio de Janeiro: Forense, 2011.

CHARTIER, Roger. A história ou a leitura do tempo. 2. ed. Belo Horizonte: Autêntica, 2015.

CRUZ, Heloísa de Faria. São Paulo em papel e tinta: periodismo e vida urbana (1890-1915). São Paulo: Impressa Oficial, 2000.

CURY, Carlos Roberto Jamil. Educação escolar e educação no lar: espaços de uma polêmica. Educação \& Sociedade, Campinas, v. 27, n. 96, p. 667-688, out. 2006.

FAGUNDES, Pedro Ernesto. Morte e memória: a necrofilia política da Ação Integralista Brasileira (AIB). Varia Historia, Belo Horizonte, v. 28, n. 48, p. 889-909, dez. 2012.

FERNANDES, Carlos. Cultura physica. 0 Paiz, Rio de Janeiro, p. 1, 10 jan. 1930.

GOIS JUNIOR, Edivaldo; MELO, Victor Andrade de; SOARES, Antônio Jorge Gonçalves. Para a construção da nação: debates brasileiros sobre educação do corpo na década de 1930. Educação \& Sociedade, Campinas, v. 36, n. 131, p. 343-360, jun. 2015.

GROPPO, Luís Antônio. Juventude: ensaios sobre sociologia e história das juventudes modernas. São Paulo: Difel, 2000.

HOLT, Richard. Contrasting nationalisms: sport, militarism and the Unitary State in Britain and France before 1914. The International Journal of the History of Sport, v. 12, n. 2, p. 39-54, 1995.

LINHALES, Meily Assbú. A escola e o esporte: uma história de práticas culturais. São Paulo: Cortez, 2009.

MOREYRA, Álvaro. Acompanhando o cambio. A Manhã, Rio de Janeiro, p. 3, 31 mai. 1935b.

MOREYRA, Álvaro. A lamentável confusão... A Manhã, Rio de Janeiro, p. 3, 20 jul. 1935a. 
O DESFILE de 15 mil athletas: o espetáculo soberbo de ante-hontem, promovido pela Associação Brasileira de Educação. A Manhã, Rio de Janeiro, p. 4, 2 jul. 1935.

O IMPORTANTE PARECER do Deputado Alberto Alvares. Jornal do Brasil, Rio de Janeiro, p. 13, 7 jul. 1936.

O SENSACIONAL concurso da 'A Manhã'. A Manhã, Rio de Janeiro, p. 7, 20 jun. 1935.

O SPORT CLUB Germania curva-se diante de Hitler. 0 Homem Livre, São Paulo, p. 2, 9 out. 1933.

OS COMICIOS da Alliança Nacional Libertadora no domingo. A Manhã, Rio de Janeiro, p. 7, 14 jun. 1935.

OS INTEGRALISTAS perseguem os desportistas do "Pereira Passos". A Manhã, Rio de Janeiro, p. 2, 2 jul. 1935.

OS RECURSOS da propaganda comunista. Jornal do Brasil, Rio de Janeiro, p. 6, 28 dez. 1937.

OS SUCESSOS do Centro Sportivo Tupynanbá. A Manhã, Rio de Janeiro, p. 3, 28 mai. 1935.

PRIM0, Jacira Cristina Santos. Tempos vermelhos: a Aliança Nacional Libertadora e a política brasileira (1934-1937). 2006. Dissertação (Mestrado em História) - Universidade Federal da Bahia, Salvador, 2006.

QUITZAU, Evelise Amgarten; SOARES, Carmen Lúcia. "A força da juventude garante o futuro de um povo": a educação do corpo no Sport Club Germania (1899-1938). Movimento, Porto Alegre, v. 16, n. 3, p. 87106, 2010.

REICHEL, Peter. Festival and cult: masculine and militaristic mechanisms of national socialism. The International Journal of the History of Sport, v. 16, n. 2, p. 153-168, 1999.

SÁ MOTTA, Rodrigo Patto. A "Intentona Comunista" ou a construção de uma legenda negra. Tempo, Niterói, n. 13, p. 189-207, jul. 2002.

SÃO ESSES os inimigos do Sigma. A Offensiva, Rio de Janeiro, p. 4, 16 set. 1936.

SAVAGE, Jon. A criação da juventude: como o conceito de teenager revolucionou o século XX. Rio de Janeiro: Rocc0, 2009.

SENNETT, Richard. 0 declínio do homem público: as tiranias da intimidade. São Paulo: Record, 2014.

SIMÕES, Renata Duarte. A educação do corpo no jornal A Offensiva (1932-1938). 2009. Tese (Doutorado em Educação) - Faculdade de Educação, Universidade de São Paulo, São Paulo, 2009.

SOARES, Carmen Lucia. Educação física: raízes europeias e Brasil. Campinas: Autores Associados, 1994.

SOB OS ASPECTOS sportivo, social, intellectual e moral, comparará o publico 0 amadorismo e 0 profissionalismo! A Manhã, Rio de Janeiro, p. 5, 13 maio 1935. 
SPURR, Michael. 'Playing for fascism': sportsmanship, antisemitism and the British Union of Fascists. Patterns of Prejudice, v. 37, n. 4, p. 359-376, 2003.

Recebido em: 10.02.2017

Aprovado em: 30.05.2017

Edivaldo Góis Junior é docente do Programa de Pós-Graduação em Educação Física da Universidade Estadual de Campinas (Unicamp).

Carmen Lucia Soares é docente do Programa de Pós-Graduação em Educação da Universidade Estadual de Campinas (Unicamp). 